\title{
Consumer Decision-Making in Multi-channel Retail: the Effects of Online Channel Media Richness and Cross-channel Integration
}

\author{
Yang Li \\ School of Management \\ University of Science and Technology of China \\ ustcly1@mail.ustc.edu.cn \\ Qian Huang \\ School of Management \\ University of Science and Technology of China \\ huangq@ustc.edu.cn
}

\author{
Hefu Liu \\ School of Management \\ University of Science and Technology of China \\ liuhf@ustc.edu.cn \\ Feng Yang \\ School of Management \\ University of Science and Technology of China \\ fengyang@ustc.edu.cn
}

\author{
Matthew K.O. Lee \\ College of Business \\ City University of Hong Kong \\ ismatlee@cityu.edu.hk
}

\begin{abstract}
While more and more retailers adopt multi-channel presence to communicate with online consumers, there still exists many differences in the level of channel integration, and accordingly, in the efficiency to reduce online transaction-specific uncertainty and promote online loyalty. This study first examines how online channel media richness affects consumers' online loyalty directly and indirectly through perceptions of information privacy concern and deception and further investigates how cross-channel integration moderates that effects. Results show that online channel media richness not only alleviates consumers' information privacy concern and perceived deception, but also enhances online loyalty. The moderating effects reveal that cross-channel integration complements online channel media richness in reducing information privacy concern and perceived deception, as well as strengthening online loyalty. Theoretical and practical implications of this study are discussed.
\end{abstract}

\section{Introduction}

Online and offline channels present different degree of shopping risks, even for the channels of the same retailer. Unlike shopping in offline store, online channel replaces physical interaction with technical interface, which enhances consumers' uncertainty about retailers' unethical practices in information exploitation and distortion. These uncertainties reduce consumers' online loyalty $[1,2]$ and cover a large percent in overall consumer complaints about e-commerce ethical issues. For example, the China Consumer Protection Network (http://www.315.gov.cn/) has reported that, in 2016, $57.22 \%$ of consumer complaints are related to e-retailer's ethical problems. Consumers' perceived ethics of online retailer refer to "consumers' perceptions about the integrity and responsibility of the company (behind the website) in its attempt to deal with consumers in a secure, confidential, fair and honest manner that ultimately protects consumers' interests" [3 p.134]. In particular, information privacy concern and perceived deception have been proposed as the transaction-specific uncertainty that depends on the retailer's ability and responsibility to reduce opportunism and secure the transaction process [4-7]. Further, scholars proposed that the simultaneous presences of online and offline channel aggravate the problem of information privacy concern [8] and perceived deception $[9,10]$ for the multi-channel retailer can collect more private information of a consumer from different channels and can also imitate the product presentation of the channel that has high reputation. Thereafter, multi-channel retailers suffer more from consumer churn for intensified uncertainty of privacy disclosure and deceptive practice in transaction process [11-13].

Prior research has mainly addressed issues of mitigating information privacy concern by relationship marking factors (e.g., retailer reputation) [14, 15], privacy policy [16, 17], or reducing perceived deception by online information presentation [18] or marketing communication $[10,19,20]$. However, these 
studies are limited in addressing transaction-specific uncertainty as a whole, which provides an incomplete conclusion for explaining consumer decision-making in an online transaction. Of particular interest is that some scholars of these studies suggest that the characteristic of online channel - media richness improves consumers' understanding of both information privacy $[21,22]$ and perceived deception [10, 20]. Media richness reflects a medium's capability to convey certain types of information that match individual's information process requirements of reducing transaction-specific uncertainty [23]. Scholars further proposed that the impact of channel media richness is associated with specific consumer decision-making in a certain channel [24], while transaction-specific uncertainty determine consumers' decision-making in online channel [13]. However, there is little work on how retailers might leverage the effect of online channel media richness to modify the effects of consumers' transaction-specific uncertainty, including information privacy concern and perceived deception, on online loyalty.

Further, extant research suggests that the efficiency of channel media richness to promote consumer decision-making is contingent on contextual characteristics [25]. As emphasized by Maity and Dass [24]), task situation, which features the established channel, should be considered in studying the impacts of channel media richness [24]. In multi-channel retail, the proliferation of digital channels provide consumers with abundant information from multiple channels to conduct online shopping task. In this case, these channels' information content could influence the relative effects of online channel media richness on decision-making and channel choice [26]. Information content is associated with the degree of information accuracy, consistency, and reliability [27]. Online channel media richness advances online shopping through informational website design that on the one hand homogenizes the sensory environment of physical store (e.g., color, product display) [28], but on the other hand integrates the information content of store (e.g., brand image, address and contact, interactive tools) [29]. Although cross-channel strategy has been widely adopted to enhance the information content of online channel [30, 31], the role of cross-channel integration on relationships between online channel media richness, transaction-specific uncertainty and channel choice have not been investigated previously. Accordingly, it is of great crucial to probe whether online channel would benefit from the cross-channel integration in promoting online consumers' decision-making.

Recently, scholars propose that information privacy concern and perceived deception can be mitigated by perception of online channel information convenience
[16], multiple cues [20, 32] and information search availability [18, 19]. Channel media richness is characterized by the extent of information variety and relevance that are related to decision-making and channel choice [23]. Thus, media richness theory (MRT) [33] provides the theoretical foundation for our study to explain whether online channel media richness helps to reduce consumers' information privacy concern and perceived deception as well as improve online loyalty [24, 34]. According to MRT, channel media richness influences consumers' evaluation and choice of that channel, and the impact of channel media richness depends on the task situation [24]. Particularly, information privacy concern and perceived deception capture the task characteristics with respect to transaction-specific uncertainty, while online channel alleviates the transaction-specific uncertainty through provision of channel media richness and thereby strengthens online loyalty. Further, we proposed that cross-channel integration [30] signifies the task situation of information content [26, 27] that might influence the relative impacts of online channel media richness on individuals' interpretation of information privacy concern [22] and perceived deception [35].

This study attempts to echo the research call of Maity and Dass [24] by investigating the specific task characteristics of online transaction-specific uncertainty and incorporating the interplay between channel media richness and task situation. From the perspective of online consumers within a multi-channel retailer, this study attempts to address two research questions: (1) Whether online channel media richness could mitigate consumers' perceptions of information privacy concern and deception in an online environment and thereby enhance online loyalty; (2) How cross-channel integration moderates the relationships among online channel media richness, information privacy concern, perceived deception and online loyalty. According to MRT [33], we expect that online channel characteristic - media richness would influence consumers' online loyalty directly and indirectly through reducing transaction-specific uncertainty - information privacy concern and perceived deception. Furthermore, cross-channel integration serves as the contextual factor of information content [26] that influences the relative impacts of online channel media richness on information privacy concern, perceived deception and online loyalty. This study attempts to advance understanding of channel media richness and transaction-specific uncertainty in a multi-channel retail.

\section{Literature review}




\subsection{Media richness theory}

Media richness theory (MRT) suggests that communication media differs in their ability to facilitate understanding of information cues and reduce uncertainties [23, 36]. The richness of media characterizes a channel's ability to communicate multiple information and promote personal decision-making within that channel [24]. According to MRT, individuals' performance in a communication context depends on both the medium characteristics (i.e., media richness) and task characteristics (i.e., uncertainty) [33]. Uncertainty refers to the absence of information that individual requires to perform the decision-making task [33]. In organizational context, organization structure and internal systems are designed to enhance media richness for reducing information uncertainty between organization and individuals [33]. Further, scholars proposed that task situation should be incorporated into explaining the effects of MRT on communication and channel choice $[24,26]$. Therefore, both the media characteristic, task characteristic and task situation within a channel should be considered to examining the effect of channel media richness on uncertainty reduction.

Recently, MRT has been extensively investigated in the context of $\mathrm{B} 2 \mathrm{C}$ e-commerce adoption and evaluation in decision-making [22, 24, 34, 37]. For instance, Brunelle [34] introduced the channel media richness to explain consumers' intention to use online store. Aljukhadar, Senecal and Ouellette [22] suggested that media richness of online channel promotes consumers' online purchasing by reducing risks through provision of realistic information. Jahng, Jain and Ramamurthy [37] use the media richness to explain consumers' change in attitude and intention toward using electronic commerce. However, these studies are limited in explaining how online channel media richness resolves shopping uncertainties under certain type of task situation (e.g., cross-channel integration), as proposed by Maity and Dass [24]. The Figure 1 shows our research model, which simultaneously considers the channel characteristic - media richness, task characteristic - transaction-specific uncertainty, as well as task situation - cross-channel integration to investigate consumers' online loyalty intention within a multi-channel retail.

\subsection{Information privacy concern and perceived deception}

Information privacy concern and perceived deception characterize the transaction-specific uncertainty that arouse consumers' concern over online shopping [4-7]. Comparing to offline shopping, consumers' perceived information privacy concern and deception would be magnified online because of the uniqueness of Internet, such as the digital environment (e.g., low entry barriers, spatial/temporal separation, and anonymity), innovative deceptive tactics (e.g., online advertisement, online promotion, personalization) [10] and numerous signals (i.e., trust mechanism, privacy policy) that may mislead online consumers [18].

Information privacy concern reflects consumer's beliefs about a retailer's inability and unwillingness to protect her personal information from improper use, disclosure to third parties, and secondary use without the consumer's consent [21]. Scholars propose that information privacy concern can be mitigated by offering benefits such as information search convenience [16] brought by media richness [24] and multi-channel use [13]. Perceived deception reflects consumers' belief about retailer's deceptive practices, such as product characteristics, price, warranty coverage, etc., that make the product seem overly attractive so as to induce greater likelihood of purchase [9]. Researchers propose that consumers would be more confident in detecting deception within a environment characterized by media richness and multiple cues $[20,35]$.

\section{Hypotheses development}

\subsection{Online loyalty}

Extant studies have treated uncertainty as the primary barrier to online transactions [21, 38]. When consumers perceive no uncertainty related to privacy concern or deception, their perceptions of expected benefits would increase, thereby increasing their willingness to relationship continuance [39, 40]. Also, a retailer's ethical behavior of information privacy protection and non-deception is considered to be a social contract that encourage consumers to have more transactions with the retailer [41]. In contrast, a high level information privacy concern leads to negative attitude [42] and risk concern toward online retailer thereby threats consumers' intention to repurchase from such a retailer [14]. Similarly, consumers' perception of deception reflects their risk concern and lacking understanding of online product information [18], which might reduce their intention to be loyal to online store [43].

Channel media richness improves consumers' attitude and decision-making confidence within that channel. Scholars proposed that media richness affects consumers' perception of online retailer's quality and favorable attitude towards future transaction with 
retailer [37]. A rich media is considered suitable for understanding difficult and complex communication issues [24], which is suggested to promote visit and purchase from the retailer [44]. Also, the informativeness of online store constitutes the quality dimension of retailer and result in consumer's online loyalty [45].

H1a: Information privacy concern is negatively related to online loyalty

H1b: Perceived deception is negatively related to online loyalty

H1c: Media richness is positively related to online loyalty

\subsection{Relationships among perceived media richness, information privacy concern, perceived deception and online loyalty}

Channel media richness provides information for effective decision-making. Scholars proposed that consumers' information privacy concern can be mitigated by offering expected benefits such as information convenience [16]. Specifically, media richness increases the degree of online communication effectiveness [46] and therefore reduce privacy concern by signaling consumers how their private information will be collected, stored, and used [21]. If the website consists of multiple cues that are indeed accurate, relevant, and credible to consumers' shopping goals and decision-making needs [46, 47], such efficiency and benefits are supposed to comfort consumers' information privacy concern with positive attitude toward the website. Also, media richness is suggested to reduce consumers' information privacy concern [21] by enhancing social presence and trust of online store [22].

As information receiver in online transaction, consumers count on the richness of online channel in discovering deceptive communication [48]. Media richness is considered helpful for consumers detecting the potential deception as leaner medium need to control more aspects of communication [20]. The shopping benefits (e.g., information search and enjoyment) brought by media richness [46, 47] are valued by consumers to reduce deception concern [18].

H2a: Perceived media richness is negatively related to information privacy concern.

H2b: Perceived media richness is negatively related to perceived deception.

\subsection{Moderating effect of cross-channel integration}

According to MRT [33], the channel media richness is determined by both channel structures and information content. It should be rationale to propose that consumers' attitude and intention toward online channel should also be influenced by the structures and information content embedded in online channel.

As online channel can reassure consumers from information privacy concern by convenient and credible decision-making environment, cross-channel integration should improve the effect of online media richness by infusing offline information and expected benefits. For instance, the online personalized web pages based on integrated online and offline transaction information signal consumers that personal information would be used in ameliorating service rather than improper use. Further, channel integration improves the efficiency of online channel media richness by impressing consumers with trustworthy and reputation image [49], which has been proved to reduce concern over information privacy [14].

Consumers' perceived deception arises when the online information presentation cannot match the consumers' knowledge about offline store of the same retailer. For instance, some online channel charges the same price for inferior product that are similar to the offline provision [9]. Though online channel media richness reduces perceived deception by interactive decision environment, a stronger degree of channel integration, which strengthens online consumers' shopping confidence through marketing communication, facilitates consumers to rely on their previous (offline) shopping experience and brand knowledge to evaluate information [50, 51]. This enhances the effects of online channel media richness by improving the information content in evaluating online deception.

According to the literature on brand extension, the familiarity and positive attitude toward a physical store can be transferred to the online channel under the same retailer [52]. Similarly, the likelihood for repeatedly using online channel may depend on the signal of online media richness in transmitting similarity between online and offline channels. For instance, channel integration brings online store with the same information and convenience as the offline store [30], consistent trust and image [49]. As a result, we expect that a strong integration of online and offline channel may expand the effects of online channel media richness in retaining consumers. In this vein, we propose that the positive effect of online channel media richness would be enhanced by cross-channel integration.

H3a: Cross-channel integration enhances the negative 
effect of online media richness on information privacy concern.

H3b: Cross-channel integration enhances the negative effect of online media richness on perceived deception.

H3c: Cross-channel integration enhances the positive effect of online media richness on online loyalty.

\section{Methodologies}

\subsection{Data collection}

To examine the hypothesized relationships, data were collected from an famous online survey platform administered on respondents recruited through Sojump [http://www.sojump.com] in China. Potential participants were first given the definition of multi-channel retailers in questionnaires, then we use a filtering question to ask the respondents whether they have "ever made a purchase from an multi-channel retailer". Respondents who make an affirmative answer were permitted to enter the following survey after filling out the name of the multi-channel retailer, while the unqualified respondents were stopped from continuing the survey. The data collection process lasted for more than two weeks and a total of 320 responses were collected. After deleting 62 questionnaires for which the respondents had failed to either meet the minimal time baseline (e.g., they completed the questionnaire less than 5 minutes) or answer key questions, 258 questionnaires were finally used for data analyze.

To test the possible non-response bias, we obeyed the procedure advocated by Armstrong and Overton [53] and conducted a t-test to compare the responses for focal constructs between the lower (e.g., first 25\%) and upper (e.g., final 25\%) quartiles of the sample. The results didn't indicate any significant difference in the response between these two groups of respondents on any of the focal constructs. Therefore, we conclude that non-response bias is not a threat in this study. We further assessed common method bias based on Harman's one-factor test [54]. Eight constructs with eigenvalues greater than 1.0 emerged from Exploratory Factor Analysis (EFA), accounting for $65.547 \%$ of the total variance. The first factor explained $30.307 \%$, which is significantly below the recommended threshold of $50 \%$. We also compared the fit between the one-factor model and the measurement model using LISREL. The results indicated that the fit of the one-factor model $\left(\chi_{350}^{2}=4414.047\right.$, RMSEA $=0.213$, $\mathrm{CFI}=0.781$, IFI=0.782, NFI=0.753, NNFI=0.764) was considerably worse $(\mathrm{p}<0.01)$ than that of the measurement model $\left(\chi_{340}^{2}=764.659, \mathrm{RMSEA}=0.0697\right.$, $\mathrm{CFI}=0.954, \quad \mathrm{IFI}=0.954, \quad \mathrm{NFI}=0.920, \quad \mathrm{NNFI}=0.949)$, thereby the common method bias is unlikely to be a serious issue in this study.

\subsection{Measurement}

We developed the survey questionnaire based on previously validated measures. All measures were assessed from consumer-centric perspective with five-point Likert scales, ranging from 1="strongly disagree" to $5=$ "strongly agree". Specifically, five items for perceived media richness were adapted from Maity and Dass [24] to describe a channel's ability to communicate richness of information. Six items were adopted from Pavlou, Liang and Xue [21] to measure consumers' information privacy concern. Four items were adapted form Riquelme, Román and Iacobucci [9] to reflect consumers' perceptions of retailer's deceptive practices. Ten items were adapted from $\mathrm{Oh}$ and Teo [30] to capture the extent to which a multi-channel retailer has the ability to integrate business functions (e.g., promotion, transaction information management, product and pricing information management, information access, and order fulfillment) across channels. Three items for measuring online loyalty were adapted from Yoo, Sanders and Moon [55]. The measurement items are presented in Appendix A. Finally, each of the four control variables (e.g., gender, age, education, and personal income) was adopted from a single-item scale.

\section{Analysis and results}

\subsection{Measurement model}

SPSS 19.0 was employed to estimate the reliability, the convergent validity and the discriminant validity of the latent constructs. As indicated in table 1, the estimated value of Cronbach's alpha ranged from 0.714 to 0.925 , which were above the benchmark value of 0.70 . Also, the estimated values of composite reliability ranged from 0.8404 to 0.9408 and were significantly greater than the benchmark value of 0.70 . Further, the loadings of all items were higher than the suggested benchmark of 0.60 . The AVE scores ranged from 0.513 to 0.7467 and were above the benchmark value of 0.50 .

The CFA results of LISREL also indicated that the fit between the measurement model and the dataset was satisfactory $\quad\left(\chi_{340}^{2}=764.659, \quad \mathrm{RMSEA}=0.0697\right.$, $\mathrm{CFI}=0.954, \mathrm{IFI}=0.954, \mathrm{NFI}=0.920, \mathrm{NNFI}=0.949)$. Taken together, the overall results suggested that the measurement model had satisfactory convergent validity. In addition, the square roots of the AVEs for all constructs were greater than the correlations between constructs (see Table 2), which confirmed the 
discrimination validity of the measurement model.

Table 1. Results of confirmatory factor analysis

\begin{tabular}{|l|c|c|c|c|c|}
\hline Constructs & Items & Loading & Composite Reliability & AVE & Cronbach's Alpha \\
\hline Cross-channel integration & 10 & $0.647-0.79$ & 0.913 & 0.513 & 0.894 \\
\hline Perceived media richness & 5 & $0.7-0.77$ & 0.8491 & 0.5298 & 0.786 \\
\hline Information privacy concern & 6 & $0.835-0.882$ & 0.9408 & 0.7262 & 0.925 \\
\hline Perceived deception & 4 & $0.826-0.892$ & 0.9218 & 0.7467 & 0.887 \\
\hline Online loyalty & 3 & $0.753-0.838$ & 0.8404 & 0.6375 & 0.714 \\
\hline
\end{tabular}

Table 2. Assessment of discriminant validity

\begin{tabular}{|l|c|c|c|c|c|c|c|c|c|c|c|}
\hline & Mean & S.D. & 1 & 2 & 3 & 4 & 5 & 6 & 7 & 8 & 9 \\
\hline 1. Cross-channel integration & 3.672 & 0.714 & $\mathbf{0 . 7 1 6}$ & & & & & & & & \\
\hline 2. Perceived media richness & 3.939 & 0.534 & $0.48^{* *}$ & $\mathbf{0 . 7 2 8}$ & & & & & & & \\
\hline 3. Perceived deception & 2.645 & 0.923 & $-0.251^{* *}$ & $-0.347^{*}$ & $\mathbf{0 . 8 6 4}$ & & & & & & \\
\hline 4. Privacy concern & 3.155 & 0.957 & $-0.264^{* *}$ & $-0.206^{* *}$ & $0.522^{* *}$ & $\mathbf{0 . 8 5 3}$ & & & & & \\
\hline 5. Online loyalty & 3.701 & 0.644 & $0.466^{* *}$ & $0.408^{* *}$ & $-0.355^{* *}$ & $-0.339^{* *}$ & $\mathbf{0 . 7 9 8}$ & & & & \\
\hline 6. Gender & - & - & 0.087 & 0.073 & $-0.138^{*}$ & -0.051 & 0.131 & - & & & \\
\hline 7. Age & - & - & 0.048 & 0.069 & $-0.131^{*}$ & $-0.178^{* *}$ & $0.145^{*}$ & $-0.165^{*}$ & - & & \\
\hline 8. Education & - & - & 0.064 & $0.176^{* *}$ & $-0.165^{* *}$ & -0.112 & $0.156^{*}$ & 0.112 & -0.061 & - & \\
\hline 9. Personal income & - & - & $0.137^{*}$ & $0.285^{* *}$ & $-0.282^{* *}$ & $-0.284^{* *}$ & $0.232^{* *}$ & $-0.15^{*}$ & $0.358^{* *}$ & 0.073 & - \\
\hline
\end{tabular}

Note: Means are assessed based on average factor scores; standard deviations (SD) and correlations are from the CFA output. The diagonal elements are the square root of the AVE. * $\mathrm{p}<0.05 ; * * \mathrm{p}<0.01$; *** $\mathrm{p}<0.001$.

\subsection{Structural model}

Figure. 1 illustrates the results of the analysis of the structural model. A good fit between the model and the datasets $\left(\chi^{2}=397.844\right.$ on 194 d.f., RMSEA $=0.0639$, $\mathrm{CFI}=0.961, \mathrm{IFI}=0.961, \mathrm{NFI}=0.928$, NNFI=0.954) was satisfied. In accordance with the expectation of Hypotheses 1a, 1c, 2a, 2b, and 3a, 3b, 3c, the majority of the hypotheses were corroborated by empirical evidence expect $\mathrm{H} 1 \mathrm{~b}$. In particular, the effect of information privacy concern on online loyalty was found negative and significant (H1a, $\beta=0.142, p<0.01$ ). Media richness is negatively related to information privacy concern $(\mathrm{H} 2 \mathrm{a}, \quad \beta=-0.524 \quad \mathrm{p}<0.001)$ and perceived deception $(\mathrm{H} 2 \mathrm{~b}, \beta=-0.776, \mathrm{p}<0.001)$ but positively related to online loyalty ( $\mathrm{H} 1 \mathrm{c}, \beta=0.427$, $\mathrm{p}<0.001)$. However, the negative effect of perceived deception $(H 1 b, \beta=-0.061, p>0.1)$ on online loyalty was not supported.

Figure. 2, 3 and 4 in Appendix A. show the moderating effects of cross-channel integration. In

\section{Discussion}

This study aims to investigate the efficiency of online channel characteristics - media richness to cope with consumers' transaction-specific uncertainty of information privacy and perceived deception. Drawing upon MRT, we propose a research model associating online channel media richness with online loyalty directly and indirectly through information privacy particular, the negative effects of online channel media richness on information privacy concern $(\beta=-0.281$, $\mathrm{p}<0.001)$ and perceived deception $(\beta=-0.217, \mathrm{p}<0.001)$ are strengthened by cross-channel integration. Also, the positive effect of media richness on online loyalty $(\mathrm{H} 3 \mathrm{c}$, $\beta=0.118, p<0.05$ ) were found to be enhanced by cross-channel integration.

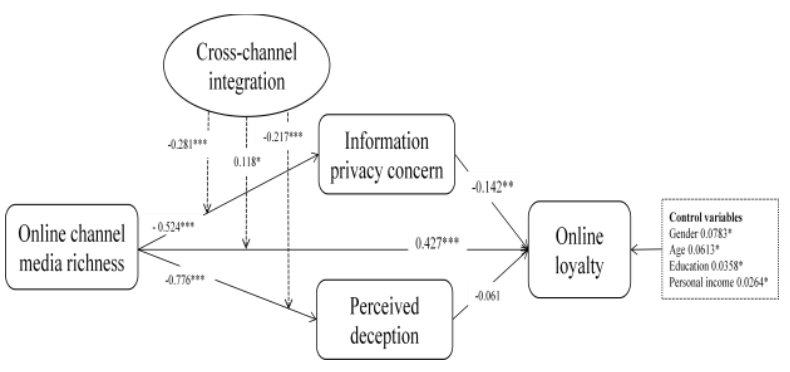

Figure 1. Research model

concern and perceived deception.

In particular, online channel media richness increases online loyalty directly (H1c). This suggests that consumers value the informational characteristics of online channel with regard to e-commerce adoption $[22,24,34]$. The negative effect of information privacy concern on online loyalty (H1a) suggests that consumers are clearly aware of the safety of personal 
information in online environment, which further affects their attitude toward future transaction. Another unexpected finding appears that perceived deception has no effect on online loyalty (H1b). This finding conforms to prior study [41], showing that the lack of understanding information would not restrain consumers from retaining in online store. These findings further support the view of Hann, Hui, Lee and Png [16] that information privacy might be of utmost concern to consumers in marketing exchange. In contrast, the perceived deception of retailer may indirectly influence loyalty through satisfaction [39] rather than bring risk that threats consumers' loyalty intention. Overall, the results bolster that a rich media environment of online store is essential to retain consumers for online purchasing.

The negative effects of media richness on information privacy concern $(\mathrm{H} 2 \mathrm{a})$ and perceived deception $(\mathrm{H} 2 \mathrm{~b})$ are supported in this study. These findings suggest that consumers indeed value information and convenience when making decision in a relative unfamiliar online store, showing that consumers who perceive the usefulness of online channel tend to be reassured from information privacy concern and perceived deception. The negative effect of online channel media richness on information privacy concern extends the proposition of Hann, Hui, Lee and Png [16] in retail context that the increased media richness helps to mitigate Internet consumers' information privacy concern. Similarly, the positive effect of online channel media richness on perceived deception suggests that transaction channel characterized by media richness would influence the degree of consumers' perceived deception in online environment [19].

In line with the expected hypotheses, cross-channel integration enhances the positive effect of online channel media richness on online loyalty and the negative effects of online channel media richness on information privacy concern and perceived deception. Investigating the moderating role of cross-channel integration is corresponding to the context research call of Palvia, Pinjani, Cannoy and Jacks [26] to explicate the effects of channel media richness on consumers' channel choice under specific task context. In particular, cross-channel integration improves the content and reliability of information embedded in online channel [30]. It suggests that the presence of physical store can enhance consumers' attitude toward online channel by integrating offline knowledge and access to online channel. These findings corresponding to the suggestion of Maity and Dass [24] that contextual factor should not be alone of task characteristic and channel characteristic in influencing consumers' decision-making and channel choice. Understanding the moderating role of cross-channel integration helps to answer prior research call for how to "deploy their multi-channel strategies in order to better meet consumers' needs" [34 p.237].

\subsection{Implications for theory and practice}

The majority of hypotheses in the research model are confirmed, which verify the MRT from which these model's hypotheses were developed. We extend the MRT by deepening our understanding of (1) how media characteristic and different types of task characteristics simultaneously influence consumers' decision on medium choice, and (2) how these effects are moderated by the contextual factor of information content.

First, investigation on the effects of information privacy concern and perceived deception on online loyalty makes a response to the research call of Román [3] to associate consumer loyalty with the consequences of consumers' perceptions regarding the ethics of online retailers. Extant studies on retailer ethics-loyalty have treated retailer ethics as an omnibus definition $[1,41,56]$ or present inconsistent findings [2, 39]. This study identifies information privacy concern and perceived deception as the transaction-specific uncertainty [4] in retailer ethics and demonstrates that information privacy concern is directly related to online loyalty while perceived deception not. Therefore, the concept of retailer ethics should not be treated as a synthesize dimension, which may incur inaccurate conclusions when it is associated with online loyalty.

Second, the efficiency of online channel media richness adds a information perceptive to predict consumers' loyalty intention of online transactions [34]. Prior study on media richness-online loyalty has focused on consumers' attitudinal change [37], social presence and trust [22], satisfaction [24] or direct relations with online purchase [34]. This study makes a difference by associating media richness with specific types of tasks that vary in the need of information [24]. The information privacy concern is corresponding to the task requirement of reducing personal information uncertainty while the perceived deception reflects the task requirement of being convinced by product information.

Third, the moderating role of cross-channel integration examines the effect of contextual factor of information content in MRT [26]. In particular, the addition of offline channel presence strengthens the effects of online channel media richness by enhancing the amount and credibility of information transmitted to consumers. Simultaneously investigating the effect of channel media richness and cross-channel integration on channel loyalty also conforms to the call of Maity 
and Dass [24] to take task situation into consideration.

Our findings offer managerial suggestions for both the pure e-retailers and multi-channel retailers. For both types of retailers, though consumers concern both uncertainties of information privacy concern and perceived deception, only information privacy concern threats consumers' willingness of online loyalty. Therefore, providing enough information to cater for consumers helps to retain consumers in online environment, such as "customizing" a Web site according to a consumer's preferences thereby increasing his or her information search convenience. Also, e-retailers can inform consumers privacy policy and personal information utilization through designing a proper online channel environment.

For multi-channel retailers, "pushing" available channels and marketing communication to prove a positive image help to alleviate consumers concern for retailers' online unethical practices. This is especially pertinent for multi-channel shopping, because most online shoppers depend on the familiarity and knowledge about the offline store of the same retailer to evaluate the online shopping environment. To exploit the advantages of physical presence, multi-channel retailers therefore should integrate the separate channels. As informed in research findings, cross-channel integration can enhance the positive effect of online channel media richness on online loyalty and the negative effects of online channel media richness on information privacy concern and perceived deception. A proper multi-channel retail setting enables the informational benefits and portfolio of services offered to the consumer. Therefore, multi-channel retailers should leverage the potential of physical presence and cross-channel integration to benefit online channel in information provision that are valued by online consumers.

\subsection{Limitation and future study}

This study initiates the first step into the antecedents and outcomes of online-transaction uncertainty in multi-channel retail. However, there still remains several limitations for inspiring future research. First, though information privacy and deception are two main ethic issues associating with online transactions, other important ethical issues are neglected in this study. For instance, fulfillment/reliability and security, which have been typical concerns for online shoppers [3]. Second, the insignificant effect of perceived deception on online loyalty needs more detailed investigation to clarify the role of product information uncertainty in consumers decision-making and channel choice. Third, other factors related to channel media richness are neglected in this study, such as product type and complexity, information overload [24], need for urgency and social interaction, need for confidentiality and need for accountability [26]. Finally, recruiting respondents from active online consumers may engender self-selection bias. Although online consumers are more familiar with online channel characteristics, incorporating enough samples from offline respondents would be more reasonable for explicating the effects of cross-channel integration.

\section{References}

[1] M.F. Diallo, C. Lambey-Checchin, "Consumers' Perceptions of Retail Business Ethics and Loyalty to the Retailer: The Moderating Role of Social Discount Practices," Journal of Business Ethics, vol. 141, 2017, pp. 435-449.

[2] H.H. Chang, S.T. Yu, L.C. Lu, "Online shoppers' perceptions of e-retailers' ethics, cultural orientation, and loyalty," Internet Research, vol. 23, 2013, pp. 47-68.

[3] S. Román, "The Ethics of Online Retailing: A Scale Development and Validation from the Consumers' Perspective," Journal of Business Ethics, vol. 72, 2007, pp. 131-148.

[4] Grabner-Kr, S. Uter, E.A. Kaluscha, "Empirical research in on-line trust: a review and critical assessment," International Journal of Human-Computer Studies, vol. 58, 2003, pp. 783-812.

[5] P. Mccole, E. Ramsey, J. Williams, "Trust considerations on attitudes towards online purchasing: The moderating effect of privacy and security concerns," Journal of Business Research, vol. 63, 2010, pp. 1018-1024.

[6] S. Grabnerkraeuter, "The Role of Consumers' Trust in Online-Shopping," Journal of Business Ethics, vol. 39, 2002, pp. 43-50.

[7] P.A. Pavlou, "Consumer Acceptance of Electronic Commerce: Integrating Trust and Risk with the Technology Acceptance Model," International Journal of Electronic Commerce, vol. 7, 2003, pp. 101-134.

[8] J. Zhang, P.W. Farris, J.W. Irvin, T. Kushwaha, T.J. Steenburgh, B.A. Weitz, "Crafting integrated multichannel retailing strategies," Journal of Interactive Marketing, vol. 24, 2010, pp. 168-180.

[9] I.P. Riquelme, S. Román, D. Iacobucci, "Consumers' Perceptions of Online and Offline Retailer Deception: A Moderated Mediation Analysis," Journal of Interactive Marketing, vol. 35, 2016, pp. 16-26.

[10] B. Xiao, I. Benbasat, "Product-Related Deception in E-Commerce: A Theoretical Perspective," Mis Quarterly, vol. 35, 2011, pp. 169-195.

[11] H.-C. Chiu, Y.-C. Hsieh, J. Roan, K.-J. Tseng, J.-K. Hsieh, "The challenge for multichannel services: Cross-channel free-riding behavior," Electronic Commerce Research and Applications, vol. 10, 2011, pp. 268-277.

[12] S.-Y. Chou, G.C. Shen, H.-C. Chiu, Y.-T. Chou, "Multichannel service providers' strategy: Understanding consumers' switching and free-riding behavior," Journal of Business Research, vol. 69, 2015, pp. 2226-2232.

[13] P.C. Verhoef, S.A. Neslin, B. Vroomen, "Multichannel consumer management: Understanding the research-shopper phenomenon," International Journal of Research in Marketing, 
vol. 24 , 2007, pp. 129-148.

[14] M.A. Eastlick, S.L. Lotz, P. Warrington, "Understanding online B-to-C relationships: An integrated model of privacy concerns, trust, and commitment," Journal of Business Research, vol. 59, 2006, pp. 877-886.

[15] Y. Li, "The impact of disposition to privacy, website reputation and website familiarity on information privacy concerns," Decision Support Systems, vol. 57, 2014, pp. 343-354.

[16] I.H. Hann, K.L. Hui, S.Y.T. Lee, I.P.L. Png, "Analyzing Online Information Privacy Concerns: An Information Processing Theory Approach," Journal of Management Information Systems, vol. 24, 2007, pp. 13-42.

[17] K.W. Wu, S.Y. Huang, D.C. Yen, I. Popova, "The effect of online privacy policy on consumer privacy concern and trust," Computers in Human Behavior, vol. 28, 2012, pp. 889-897.

[18] I.P. Riquelme, S. Román, "The Influence of Consumers' Cognitive and Psychographic Traits on Perceived Deception: A Comparison Between Online and Offline Retailing Contexts," Journal of Business Ethics, vol. 119, 2014, pp. 405-422.

[19] L. Zhou, D. Zhang, "Typing or messaging? Modality effect on deception detection in computer-mediated communication," Decision Support Systems, vol. 44, 2007, pp. 188-201.

[20] K.W. Rockmann, G.B. Northcraft, "To be or not to be trusted: The influence of media richness on defection and deception," Organizational Behavior \& Human Decision Processes, vol. 107, 2008, pp. 106-122.

[21] P.A. Pavlou, H. Liang, Y. Xue, "Understanding And Mitigating Uncertainty In Online Exchange Relationships: A Principal--Agent Perspective," Mis Quarterly, vol. 31, 2007, pp. 105-136.

[22] M. Aljukhadar, S. Senecal, D. Ouellette, "Can the Media Richness of a Privacy Disclosure Enhance Outcome? A Multifaceted View of Trust in Rich Media Environments," International Journal of Electronic Commerce, vol. 14, 2010, pp. 103-126.

[23] R.L. Daft, R.H. Lengel, L.K. Trevino, "Message Equivocality, Media Selection, and Manager Performance: Implications for Information Systems," Mis Quarterly, vol. 11, 1987, pp. 355-366.

[24] M. Maity, M. Dass, "Consumer decision-making across modern and traditional channels: E-commerce, m-commerce, in-store," Decision Support Systems, vol. 61, 2014, pp. 34-46.

[25] R.W. Zmud, M.R. Lind, F.W. Young, "An Attribute Space for Organizational Communication Channels," Information Systems Research, vol. 1, 1990, pp. 440-457.

[26] P. Palvia, P. Pinjani, S. Cannoy, T. Jacks, "Contextual constraints in media choice: Beyond information richness," Decision Support Systems, vol. 51, 2011, pp. 657-670.

[27] W.L. Yang, D.M. Strong, B.K. Kahn, R.Y. Wang, "AIMQ: a methodology for information quality assessment," Information \& Management, vol. 40, 2002, pp. 133-146.

[28] O. Emrich, P.C. Verhoef, "The impact of a homogenous versus a prototypical Web design on online retail patronage for multichannel providers $\hat{\xi}, "$ International Journal of Research in Marketing, vol. 32, 2015, pp. 363-374.

[29] D. Herhausen, J. Binder, M. Schoegel, A. Herrmann,
"Integrating bricks with clicks: retailer-level and channel-level outcomes of online-offline channel integration," Journal of retailing, vol. 91, 2015, pp. 309-325. [30] L. Oh, H. Teo, "Consumer Value Co-creation in a Hybrid Commerce Service-Delivery System," International Journal of Electronic Commerce, vol. 14, 2010, pp. 35-62.

[31] K. Melis, K. Campo, E. Breugelmans, L. Lamey, "The impact of the multi-channel retail mix on online store choice: Does online experience matter?," Journal of Retailing, vol. 91, 2015, pp. 272-288.

[32] S.S. Kahai, R.B. Cooper, "Exploring the Core Concepts of Media Richness Theory: The Impact of Cue Multiplicity and Feedback Immediacy on Decision Quality," Journal of Management Information Systems, vol. 20, 2004, pp. 263-299.

[33] R.L. Daft, R.H. Lengel, "Organizational Information Requirements, Media Richness And Structural Design," Management Science, vol. 32, 1986, pp. 554-571.

[34] E. Brunelle, "Introducing Media Richness into an Integrated Model of Consumers' Intentions to Use Online Stores in Their Purchase Process," Journal of Internet Commerce, vol. 8, 2009, pp. 222-245.

[35] A. Vrij, S. Mann, "Detecting Deception: The Benefit of Looking at a Combination of Behavioral, Auditory and Speech Content Related Cues in a Systematic Manner," Group Decision and Negotiation, vol. 13, 2004, pp. 61-79.

[36] K.S. Suh, "Impact of communication medium on task performance and satisfaction: an examination of media-richness theory," Information \& Management, vol. 35, 1999, pp. 295-312.

[37] J. Jahng, H. Jain, K. Ramamurthy, "Effects of interaction richness on consumer attitudes and behavioral intentions in e-commerce: some experimental results," European Journal of Information Systems, vol. 16, 2007, pp. 254-269.

[38] A. Dimoka, Y. Hong, P.A. Pavlou, "On product uncertainty in online markets: theory and evidence," Social Science Electronic Publishing, vol. 36, 2011, pp. 395-426.

[39] S. Román, "Relational Consequences of Perceived Deception in Online Shopping: The Moderating Roles of Type of Product, Consumer's Attitude Toward the Internet and Consumer's Demographics," Journal of Business Ethics, vol. 95, 2010, pp. 373-391.

[40] H. Xu, X. Luo, J.M. Carroll, M.B. Rosson, "The personalization privacy paradox: An exploratory study of decision making process for location-aware marketing," Decision Support Systems, vol. 51, 2011, pp. 42-52.

[41] Y.B. Limbu, M. Wolf, D. Lunsford, "Perceived ethics of online retailers and consumer behavioral intentions: The mediating roles of trust and attitude," Journal of Research in Interactive Marketing, vol. 6, 2012, pp. 133-154.

[42] J.A. Castañeda, F.J. Montoro, "The effect of Internet general privacy concern on consumer behavior," Electronic Commerce Research, vol. 7, 2007, pp. 117-141.

[43] W.S. Kwon, S.J. Lennon, "What induces online loyalty? Online versus offline brand images," Journal of Business Research, vol. 62, 2009, pp. 557-564.

[44] T.P. Liang, H.J. Lai, "Effect of store design on consumer purchases: an empirical study of on-line bookstores," Information \& Management, vol. 39, 2002, pp. 431-444.

[45] M. Wolfinbarger, M.C. Gilly, "eTailQ: dimensionalizing, measuring and predicting etail quality," Journal of Retailing, 
vol. 79, 2003, pp. 183-198.

[46] R.F. Otondo, J.R.V. Scotter, D.G. Allen, P. Palvia, "The complexity of richness: Media, message, and communication outcomes," Information \& Management, vol. 45, 2008, pp. 21-30.

[47] T.L. Childers, C.L. Carr, J. Peck, S. Carson, "Hedonic and utilitarian motivations for online retail shopping behavior," Journal of Retailing, vol. 77, 2001, pp. 511-535.

[48] J.R. Carlson, J.F. George, "Media Appropriateness in the Conduct and Discovery of Deceptive Communication: The Relative Influence of Richness and Synchronicity," Group Decision and Negotiation, vol. 13, 2004, pp. 191-210.

[49] H. Schramm-Klein, G. Wagner, S. Steinmann, D. Morschett, "Cross-channel integration-is it valued by consumers?," The International Review of Retail, Distribution and Consumer Research, vol. 21, 2011, pp. 501-511.

[50] K. Melis, K. Campo, L. Lamey, E. Breugelmans, "A Bigger Slice of the Multichannel Grocery Pie: When Does Consumers' Online Channel Use Expand Retailers' Share of Wallet?," Journal of Retailing, vol. 92, 2016, pp. 268-286.

\section{Appendix A. Moderating effects}

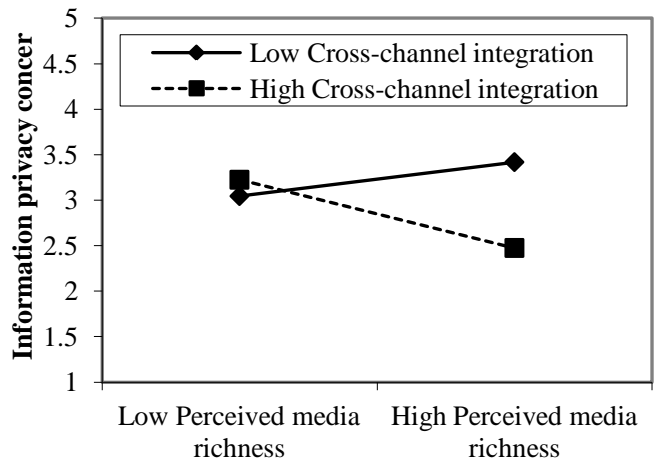

Figure 2. Moderating effect of $\mathrm{CCl}$ on information privacy concern
[51] J. Avery, T.J. Steenburgh, J. Deighton, M. Caravella, "Adding bricks to clicks: Predicting the patterns of cross-channel elasticities over time," Journal of Marketing, vol. 76, 2012, pp. 96-111.

[52] W.S. Kwon, S.J. Lennon, "Reciprocal Effects Between Multichannel Retailers' Offline and Online Brand Images," Journal of Retailing, vol. 85, 2009, pp. 376-390.

[53] J.S. Armstrong, T.S. Overton, "Estimating nonresponse bias in mail surveys," Journal of marketing research, vol. DOI, 1977, pp. 396-402.

[54] P. Podsakoff, S. MacKenzie, J. Lee, N. Podsakoff, "Common Method Bias in Behavioral Research: A Critical Review of the Literature and," vol. DOI, 2003, pp.

[55] C.W. Yoo, G.L. Sanders, J. Moon, "Exploring the effect of e-WOM participation on e-Loyalty in e-commerce," Decision Support Systems, vol. 55, 2013, pp. 669-678.

[56] S. Román, "The Impact of Ethical Sales Behaviour on Consumer Satisfaction, Trust and Loyalty to the Company: An Empirical Study in the Financial Services Industry," Journal of Marketing Management, vol. 19, 2003, pp. 915-939.

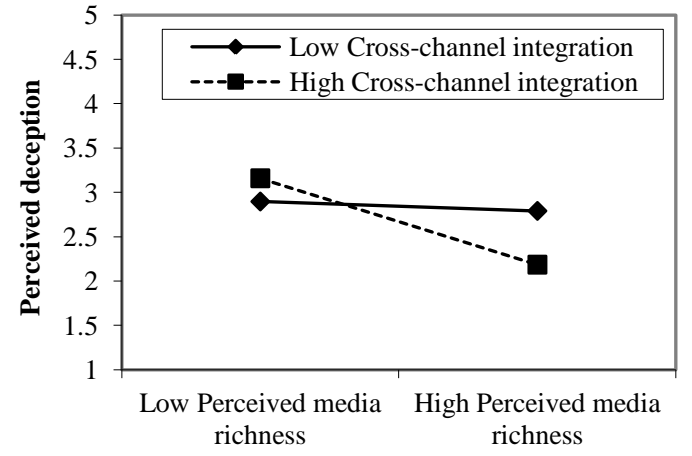

Figure 3. Moderating effect of $\mathrm{CCl}$ on perceived deception

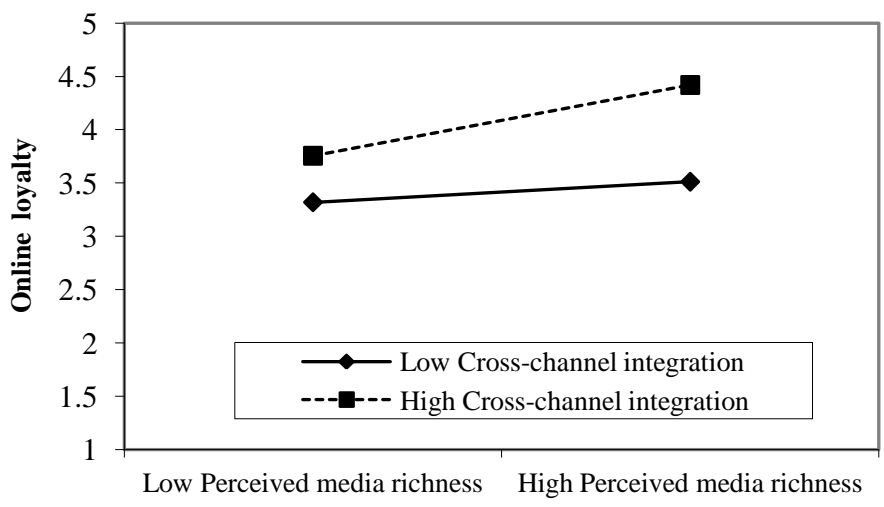

Figure 5. Moderating effect of $\mathrm{CCl}$ on the relationships between perceived media richness and online loyalty 